\title{
Integrating Nanoscience Activities in Enhancing Malaysian Secondary School Students' Understanding of Chemistry Concepts
}

\author{
Kah-Heng Chua ${ }^{1^{*}}$, Mageswary Karpudewan ${ }^{2}$ \\ ${ }^{1}$ University of Malaya, MALAYSIA \\ 2 Universiti Sains Malaysia, MALAYSIA
}

Received 19 April 2019 • Revised 25 May 2019 • Accepted 18 July 2019

\begin{abstract}
This study reports the effectiveness of nanoscience activities in enhancing secondary school students' understanding of two chemistry concepts: structure of atom and acid and bases. For the purpose of this study, quasi experiment was employed to 163 Grade 10 students from the Northern Region of Malaysia. Sample from the experimental group was exposed to a series of nanoscience activities lasted for 10 weeks. Students' understanding on the two chemistry concepts was tested using Chemistry Achievement Test (CAT). The CAT consists of multiple-choice questions and openended questions. Data obtained from CAT was analysed using one-way ANCOVA to identify the effectiveness of nanoscience activity in enhancing students' understanding of chemistry concepts. The findings show that there were statistically significant differences between experimental and control groups' mean scores $(F(1,160)=167.82$, $\left.p<0.05 \eta_{p}^{2}=0.512\right)$ with the experimental group students reporting higher mean. The ANCOVA result indicated experimental group students' understanding of chemistry concepts significantly higher than the comparison group. The qualitative analysis of open-ended responses further supports findings obtained from the quantitative analysis. The study suggests that integrating nanoscience into the contemporary teaching of chemistry is relevant and appropriate.
\end{abstract}

Keywords: acid and bases, chemistry education, nanoscience, secondary school, structure of the atom, understanding of chemistry concepts

\section{INTRODUCTION}

Chemistry, by nature, is a highly conceptual subject. Students' understanding of chemistry concepts is an important area of research in chemistry education (Ben-Zvi, Eylon, \& Silberstein, 1988; Gabel, 1988). In schools, chemistry concepts such as the structure of the atom, state of matter, salts, acids and bases are some fundamental concepts students required to master to facilitate the understanding more advance chemistry concepts at higher level of learning (Kirbulut \& Beeth, 2013; Levy Nahum, Mamlok-Naaman, Hofstein, \& Taber, 2010; McWeeny, 2007). There are available studies dictated that students failed to understand fundamental chemistry concepts correctly (Osman \& Sukor, 2013), eventually struggled to learn chemistry at a higher level (Aydeniz \& Kotowski, 2012; Canpolat, 2006). Besides the prerequisite needs to learn advanced concepts, these concepts form an integral part of everyday phenomena as it has a close connection in explaining the phenomena in a scientific manner (Kirbulut \& Beeth, 2013). In order to sustain students' engagement in chemistry, it is necessary for students to possess a good grasp of knowledge about the subject matter (Kennedy, 1998).

Chemistry in secondary school consists of both qualitative and quantitative aspects. Students need to understand and master both aspects for them to solve chemistry related problems. Internationally, many reports revealed that students have difficulties in understanding various chemistry concepts. These include chemical

(C) 2020 by the authors; licensee Modestum Ltd., UK. This article is an open access article distributed under the terms and conditions of the Creative Commons Attribution License (http://creativecommons.org/licenses/by/4.0/). \chuakh@um.edu.my chuakahheng@yahoo.com (*Correspondence) 


\section{Contribution of this paper to the literature}

- As understanding of contemporary natural phenomena requires science to be multifaceted, nanoscience, as introduced in this study for the secondary curriculum, is an example of a multifaceted interdisciplinary science.

- Studies that documented about nanoscience is prevalent in the manufacturing process and the undergraduate level chemistry. Suggestions from this study to have nanoscience in secondary curriculum bridges the gap on lacking of such curriculum in secondary education.

- Through this study a new curriculum on nanoscience is proposed. This new curriculum would be useful for educators and teachers intend to integrate nanoscience in their usual classroom.

bonding (Ozmen, 2004); acids and bases (Demircioglu, Ayas, \& Demircioglu, 2005), the structure of atom (Chiu, 2007), chemical formulae and chemical equation (Agung \& Schwartz, 2007); and Salts (Chandrasegaran, Treagust, \& Mocerino, 2007). Students' poor acquisition of chemistry knowledge is also an alarming stage in Malaysia. Various local researches had highlighted that Malaysian students have a limited understanding of chemistry concepts. For instance, chemical equilibrium (Karpudewan, Treagust, Mocerino, Won \& Chandrasegaran, 2015), acid and bases (Surif, Ibrahim \& Moktar, 2012), atomic structure, chemical equation and formulae, chemical bonding, acid and bases, and salts (Osman \& Sukor, 2013), and concepts related to matter (Sim \& Daniel, 2014).

Researchers asserted that through student-centred teaching approach, it is possible for students to have a better understanding of chemistry concepts (Ozmen, Demircioglu, Burhan, Naseriazar, \& Demircioglu, 2012; Park, Light, Swarat, \& Denise, 2009; Yakmaci-Guzel \& Adadan, 2013). Nanoscience is interdisciplinary in nature (Chari, Howard, \& Bowe, 2012; Hey, Joyce, Jennings, Kalil, \& Grossman, 2009) and nanoscience when used in the chemistry classroom reported to improve the students' learning (Allamel-Raffin, 2011; Mehraban, 2016) as the nanoscience curriculum requires students to learn about the real-world circumstances (Blonder \& Sakhnini, 2012; Bradley, Castle, \& Chaudhry, 2011). Nanoscience is identified as a contemporary science which entails on numerous applications closely related to students' everyday life (Ghattas \& Carver, 2012; Santiago \& Morell, 2006). However, to date, studies investigating nanoscience and understanding of chemistry concepts are minimal.

\section{Background}

The students' understanding of chemistry is not much different from a blind people's understanding of an elephant. Most of the chemical concepts such as an atom, molecules, electrons, ions, and chemical bonding are invisible to the naked eyes. The conceptualization of these concepts is usually facilitated using semantic models or/and mathematical representation. Holme, Luxford, and Brandriet (2015) reflected that students had attained the understanding of the concepts if they were able to perform any one of the five fragments: (1) transfer: student able to apply core chemistry ideas to chemistry situations that are novel to them, (2) depth: student able to reason about core chemistry ideas using skills that go beyond rote memorization or algorithmic problem solving, (3) predict: student able to expand situational knowledge to predict and/or explain behaviour of chemical system, (4) problem solving: student able to demonstrate the critical thinking and reasoning involved in solving problems including laboratory measurement, and (5) translate: student able to translate across scales and representations.

In learning chemistry, students are required to see beyond the symbols (microscopic, subatomic and macroscopic levels) and make connections among the different levels when describing an observation or explaining a process (Kozma, 2003). Meyer (2005) claimed that introducing and emphasizing the particulate nature of matter (sub-microscopic level) during the chemistry class helped the students to link the particulate nature of matter to another level (macroscopic level and symbolic level). However, such a phenomenon is rarely practiced in chemistry classes in school (Gabel, 1993). During the learning, integration of different types of information from different level allowed the information to be coherently structured and permits the understanding among the students. For example, understanding of single concept such as diffusion into more complex concepts such as the movement of particles based on kinetic theory of matter was built coherently based on few underlying concepts.

The topic on acids and bases has been reported to be difficult for high school students for almost few decades (Burns, 1982). Acids and bases consisted of abstract concepts and difficult to understand because students should have had an in-depth understanding of particulate nature of matter, solutions, chemical reactions, and chemical equilibrium (Cetin-Dindar \& Geban, 2017). Several studies have shown that understanding the nature of acids and bases can be very confusing. For example, Chiu (2004), had pointed out that $13 \%$ of junior and senior high school students and $34 \%$ of senior high school students facing difficulties to differentiate weak electrolytes. She also found out that also found that $19 \%$ of junior and $9 \%$ of senior high school students believed that a weak electrolyte exists as molecules in water. Huang (2004) found out that students were unable to differentiate between the property of acids and bases. In the study, Huang claimed that nearly half of students assumed that soapsuds were neutral because they were not harmful to human skin or clothes, while one-third of students thought that a mixture of a 
solution of sodium bicarbonate and ethanoic acid was neutral because they produced a neutralization reaction when mixed. At the same time, about one-quarter of students assumed that all acids and bases were toxic. In another study conducted by Kala, Yaman, \& Ayas (2013) investigating students' understandings of acids and bases had summarized that some of the students were found to have a poor understanding about $\mathrm{pH}$ and $\mathrm{pOH}$.

Structure of the atom is another fundamental concept in chemistry as it is the basis of all other topics in chemistry (Sarikaya, 2007). Students with a poor understanding of atomic structure might face difficulties to grasp concepts of other areas of chemistry. A study by Sequeira and Leite (1991) revealed that students showed a reasonable understanding of the size and the structure of the atom. The same study showed that $29 \%$ of the eighth graders, and $10 \%$ of ninth graders students unable to respond when asked about the atom.

Studies had shown that students' understanding of the structure of atom could improve through various teaching approach. Salame, Sarowar, Begum, and Krauss (2011) in their study found out that the majority of students do not understand topic related to the structure of the atom. Students resist changing their views and explanations in conventional teaching or lecturing classrooms because the teacher-centred teaching approach does not always cause conceptual change as they do not address the fundamental principle that knowledge is constructed in the mind of the learner.

A poor understanding implicates that, teaching that happened in the classroom failed to benefit the students. Several studies conducted by different researchers showed that pedagogical approach influenced students' understanding of chemistry concepts (Dai, 2004; Gou, 2003). A study conducted by Levy Nahum et al. (2007) asserted that systemic and proper teaching approach that developed in the study have significantly increased students' understanding in the chemical bonding as compared to the traditional pedagogical approach. Cheung (2011) asserted that teaching approach has a great influence towards students' understanding of chemistry concepts. Cheung highlighted that teacher should encourage students to think critically, ask different questions and provide opportunities for students to become active learners with more student-centred instruction. Numerous studies demonstrated that understanding of chemistry concepts could be improved by using a constructivist approach (Demircioglu et al., 2005; Tal, 2004; Tobin \& Gallagher, 1987). For instance, Johnson and Johnson (1989) have proposed the constructivist teaching approach, and they pointed out that the advantages of using a constructivist teaching approach such as promote cooperation between students, increase hands-on experience and ability to link to real life, and enhance participation and socialization. Snyder (2000) also pointed out that students have a better understanding in a constructivist classroom which encourages students to play an active role in the learning process. This supports the process of assimilation and accommodation through the social interaction with peers in the classroom.

Based on the evidence shown above, it is clear that to enhance students' understanding of chemistry concepts; it would be advisable to emphasize the teaching and learning approach which put more weight on the student. Researches had evidenced that conventional teaching approaches were unable to create a huge impact to cause conceptual change among students. Hence, it is essential to engage students in learning whereby students have a higher authority to participate in the learning, discussion, decision making, and responsible for the construction of a conceptual understanding of chemistry concepts. A teaching approach that highly involves students with the

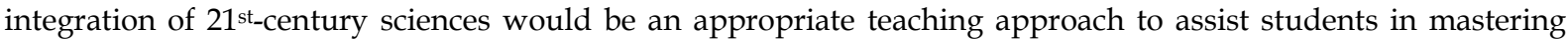

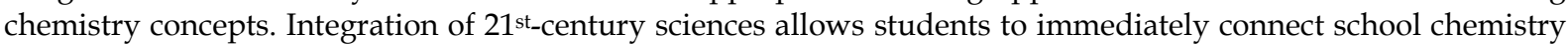
with their daily life occurring (Blonder \& Dinur, 2012; Blonder \& Sakhnini, 2012; Laherto, 2012; Schank, Wise, Stanford, \& Rosenquist, 2009). One possible way is by having nanoscience in the curriculum as it is noted that nanoscience act as a bridge which links the chemistry concepts with daily life application (Varadan, Pillai, Mukherji, Dwivedi, \& Chen, 2010).

Studies have shown that the use of nanoscience activities in teaching and learning have created various positive outcomes. A study by Blonder and Sakhnini (2012) showed that nanoscience activities developed a positive impact to the 9th-grade students' learning of chemistry and it is an effective approach in supporting students' understanding. In another study done by Blonder and Dinur (2012), constructivist pedagogy integrated with the nanoscience activities was conducted with high school students. This teaching approach of moving from a teachercentred pedagogy to a student-centred pedagogy motivated the participating students to learn more about chemistry (Blonder \& Dinur, 2012). In a research carried out by Ibrahim and Karpudewan (2013), nanosciencebased constructivist teaching approach managed to increase secondary school students' attitude towards learning biology.

Nanoscience is an approach that requires looking into the microscopic level of atoms and molecules. It involves research to discover new behaviours and properties of materials with dimensions at the nanoscale, which ranges roughly from 1 to 100 nanometers (nm) (National Nanotechnology Initiative, 2008). Nanoscience activities are a series of activities designed to help students increase their conceptual understanding of chemistry. Nanoscience activities can be understood as an alternative teaching approach used for laboratory activities. It consists of handson nanoscience activities based on the chemistry concepts. The combination of nanoscience activities into the 
laboratory was expected to draw similar result as suggested by previous researchers where laboratory activity have the feasibility to enhance students' conceptual understanding (Mbajiorgu \& Reid, 2006; Ozmen et al., 2012; Supasorn, 2012). According to Jones, Andre, Superfine, and Taylor (2003), a significant improvement in understanding of chemistry-related concepts was noticed when students involved in nanoscience hands-on activities. Meanwhile, Dori, Dangur, Avargil, and Peskin (2014) also claimed that through nanoscience activities, students apply and connect their chemical understanding to interdisciplinary aspects and everyday applications.

In a constructivist learning environment, students were encouraged and required to interact among themselves. Such a situation was to ensure that students were communicating, carried out the discussion between students to exchange ideas, and constructing new ideas while handling the nanoscience hands-on activities. During the laboratory activities, students were actively engaged in the learning process while chemistry teacher act as a facilitator to facilitate the learning process. While engaging in the nanoscience activities, it reflected that students were actively involved in the learning process in constructing new ideas. This was aligned with the principal of constructivist theory whereby students were involved in learning and constructing new knowledge.

\section{Research Questions}

Through this study, an attempt was made to employ nanoscience activities to teach the students on several chemistry concepts. The study seeks to answer the following research question "Is there any statistically significant difference between the experimental and control group's chemistry achievement test post-test mean scores after controlling the pre-test scores?"

\section{RESEARCH METHODOLOGY}

\section{Sampling Procedure of the Study}

For this study, a total of 163 students from four intact classes participated in this study. Intact classes were used in this study as it is unlikely to obtain approval to randomly select and remove selected students for this study from the participating schools (Gay, Mills, \& Airasian, 2009). The participating school was from Northeast of Penang Island District, one of the northern regions states in Peninsular of Malaysia. Participating school had eight Grade 10 pure science classes in total with approximately 38 to 42 students in a class. Of the eight classes, four classes were randomly selected for this study. These classes were randomly assigned to experimental and control groups based on the intact class principal. The experimental group consisted of 80 students, and 83 students were in the control group. The participants of this study comprise of secondary science stream students between the ages of 15 to 16 years old (Grade 10). The research was carried out for 10 weeks. In Malaysia, chemistry is offered as an elective subject to Grade 10, and Grade 11 science stream students and chemistry is a compulsory subject for students in the participating school.

\section{Research Design}

The quasi-experimental method was applied in this study. According to Shadish, Cook, and Campbell (2002), quasi-experimental with experimental and control group design is one of best design to be used to measure the effectiveness of treatment. The effect of the treatment was measured quantitatively using Chemistry Achievement Tests. The open-ended responses provided in test were also qualitatively analysed. The qualitative findings were used to understand the quantitative findings (Chua \& Karpudewan, 2017; Chua, Karpudewan, \& Chandrakesan, 2017; Shamuganathan \& Karpudewan, 2017; Zangori, Vo, Forbes, \& Schwarz, 2017).

In this study, both the control and experimental groups were in the same school. Having both groups in the same school permits the groups to be taught by the same teacher. With this, teacher effect has been nested. Additionally, having both groups in the same school also controls other external variables such as climate, learning environment, and laboratory facilitates available which might contribute to the results as well. On the contrary, having both groups in the same school creates diffusion effect as there are possibilities for the students from the groups to interact. The diffusion effect is controlled in this study by keeping the two groups of students as separate as possible during the treatment period (Creswell, 2014, p. 175) and deemphasizing the fact that there is an experiment in progress and by encouraging teachers to avoid accentuating the differences between the two groups (Vockell \& Asher, 1995). 


\section{Instrument}

\section{Chemistry Achievement Test (CAT)}

CAT I and CAT II were administered as pre-test and post-test for the control group and experimental group during the $1^{\text {st }}$ week and the $10^{\text {th }}$ week respectively. Both set of CAT I and CAT II used the same items but with a different order in the arrangement. The decision to use this method was made based on the guideline proposed by Cohen, Manion, and Morrison (2007) which stated that the items drawn for the pre-test and the post-test should have similar content and level of difficulty. Altogether there were 30 multiple choices questions and six open-ended questions. Each correct answer in the multiple-choice question was awarded with one mark, meanwhile zero mark was given to the wrong answer. Similarly, marks were given accordingly to the answer provided by the students for the open-ended questions. In total, the open-ended questions were made up of 53 marks. Under each openended question it has sub questions that test on students' understanding on chemistry concepts. The items in CAT I and CAT II was selected from national public examination questions which used to assess students' understanding on the two different chemistry concepts. There were two chemistry concepts evaluated in CAT. The concepts were the structure of the atom and acids and bases. An example of the multiple choices question and open-ended question in the test are as follows:

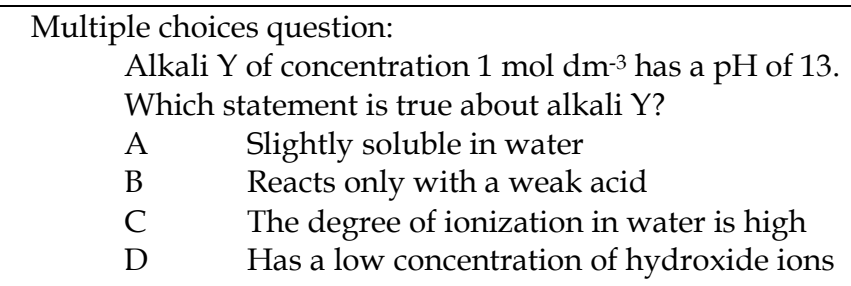

Open-ended question:

1. Diagram 1 shows the inter-conversion of the three states of matter, $\mathrm{X}, \mathrm{Y}$ and $\mathrm{Z}$ of water.

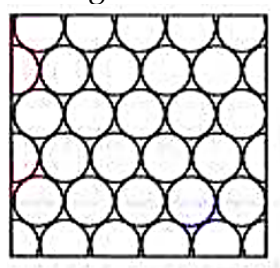

$\mathrm{X}$

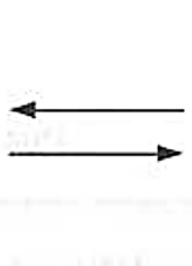$$
\text { . }
$$

.

a) What type of particles is found in water?

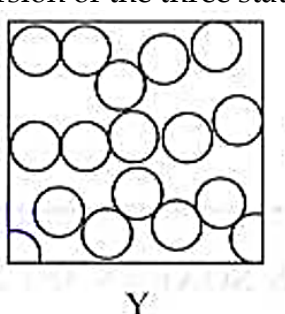

Y

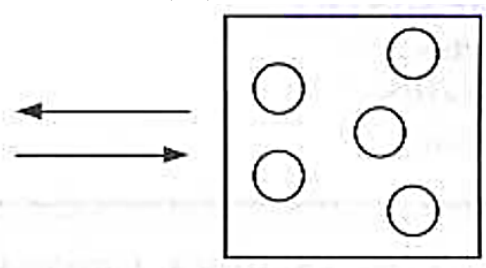

Z

Diagram 1

[1 mark]

b) Under the room temperature, at what temperature does ice change to water?

[1 mark]

In both CAT I and CAT II, students' understanding of the structure of the atom and acids and bases were measured. Students' understanding was measured using chemistry achievement test, students who able to perform and score in the achievement test indicated that they understand the chemistry concepts. For the structure of the atom, the questions assessed understanding on the property of compound and element; changes in the state of matter; and diffusion process. For acid and bases, the questions assessed students' knowledge on the properties of acid and bases; neutralization process; and ionization of acids. Additionally, the ability of the students to calculate the concentration of acids and bases were also assessed. The questions in the CAT I and CAT II is align with the chemical concepts addressed in the nanoscience activities and the traditional teaching and learning method. The two chemical concepts highlighted in nanoscience activities are structure of the atom and acids and bases.

\section{Nanoscience Activities Manual}

A manual consisting of eight nanoscience activities was developed prior to the study. The nanoscience activities manual consisted of eight nanoscience activities tailored based on the Malaysia secondary school syllabus (KBSM). 
The nanoscience activities were designed to cover two main difficult concepts in chemistry which are structure of the atom and acids and bases. There were five activities cater for the concept of structure of the atom. Meanwhile the concepts of acids and bases was covered by another three activities. Each activity integrated relevant chemistry concept into nanoscience activity. Each manual starts with pre-laboratory questions. The primary purpose of having the pre-laboratory questions was to test students' prior knowledge about the concept discussed and encourage students to think before the laboratory activity was carried out. This was followed by a pre-laboratory discussion which provided some background information related to nanoscience. The aim of the study, materials, and apparatus used as well as the procedures were also included in the activity manual. The activity manual ended with post-laboratory questions. The rationale of having a post-laboratory discussion was to help students accommodate new concepts, able to explain the concepts, and applied the newly learned concepts to solve problems and open up a new area of inquiry.

\section{Pilot study}

Prior to the actual study, a pilot test was conducted to collect preliminary data to check and ensure the reliability and the validity of the CAT. For this purpose, 43 Grade 10 students were involved. The KR-20 value for the CAT was reported at the value of 0.87 . For the validity, three experience chemistry teachers examined the CAT questions, and they agreed with the CAT items and reported that the items were appropriate to test students' understanding of chemistry concepts. Meanwhile, the nanoscience laboratory manual was sent to three experienced chemistry teachers with more than ten years of teaching experience for validation purposed.

\section{Treatment}

This study was conducted over a period of 10 weeks. For the control group, the teaching was instructed using the traditional method while the experimental group was instructed using nanoscience laboratory activities. Both the experimental groups and control groups were taught on the two chemical concepts which is structure of the atom and acids and bases by their usual chemistry teacher. For the control group, both chemical concepts were conducted using a more teacher-centred teaching approach. The students were required to use their textbook and practical book which was certified by the Ministry of Education Malaysia. In the textbook, students were taught the fundamental concept and theory and followed by exercises. For instance, when teaching the concept of diffusion, teacher start with definition of diffusion, followed by diffusion process in different state (ie solid, liquid and gas). Teacher will either demonstrate or require students to carry out the diffusion hands-on activity for three different state of matter. The diffusion concept will end with exercise or pass year public examination questions as an enhancement for concept learned.

In contrast, the experimental group students were taught using nanoscience activities teaching approach. For instance, the experimental group students performed a nanoscience activity on 'serial dilution of scented food colouring' to learn about the concept of diffusion process. The activity was performed using nine test tubes filled with the same level of water. Scented food colouring was dropped into the test tubes with water. Once the colour is well mixed in the test tubes, $1 \mathrm{~mL}$ of the mixture was transferred from the test tube labelled 1 to 2,2 to 3 and subsequently till the end. Students recorded the changes in colour and smell. Diffusion is the net movement of atoms or molecules from a region of high concentration to a region of low concentration. When scented food colouring mixes with water, it gives colour and at the same time produce some smell. However, when more and more water was added, the colour fades at a faster rate than the smell. This illustrates that diffusion did not end when the colour disappears. In other words, diffusion continues even when the process is not noticeable to our eyes. Additionally, the activity also made the students aware of small-scale (nanoscale) matters that are not obvious to our eyes, apparently could be identified by other senses.

On the contrary, the control group student learns about diffusion through diffusing potassium permanganate in water whereby during this process students were asked to notice how the purple colour potassium permanganate travels through the water. The experimental group students expanded the learning to the level of recognizing the existence of matter that is not visible for human's naked eyes (at the nanoscale). However, for the control group, diffusion is understood from what was observed. Beyond this, for the control group, diffusion has ended.

\section{Procedure for Data Analysis}

For CAT, ANCOVA analysis was performed to analyse the post-test result by controlling the covariate. Each correct answer in the multiple-choice question was awarded one mark. Meanwhile, zero marks were given to the wrong answer. Meanwhile, for the open-ended questions, marks were given according to the answer given by students. The answers were marked based on the marking scheme. The rubric was provided to teachers as the guideline for the marking of open-ended questions. One mark was awarded for each correct answer and 0 marks 
Table 1. Analysis of Covariance of the Mean Scores Obtained from Understanding in Chemistry Concepts

\begin{tabular}{ccccccc}
\hline Source & Sum of Squares & df & Mean Square & $\mathbf{F}$ & Sig. & $\boldsymbol{\eta}_{\mathbf{p}}{ }^{2}$ \\
\hline Pre-test & 4990.77 & 1 & 4990.77 & 273.13 & 0.00 & 0.631 \\
\hline Treatment & 3066.60 & 1 & 3066.60 & 167.82 & 0.00 & 0.512 \\
\hline Error & 2923.65 & 160 & 18.27 & & & \\
\hline Total & 766713.00 & \multicolumn{7}{l}{}
\end{tabular}

Minimum and Maximum Score for Open-Ended

Questions

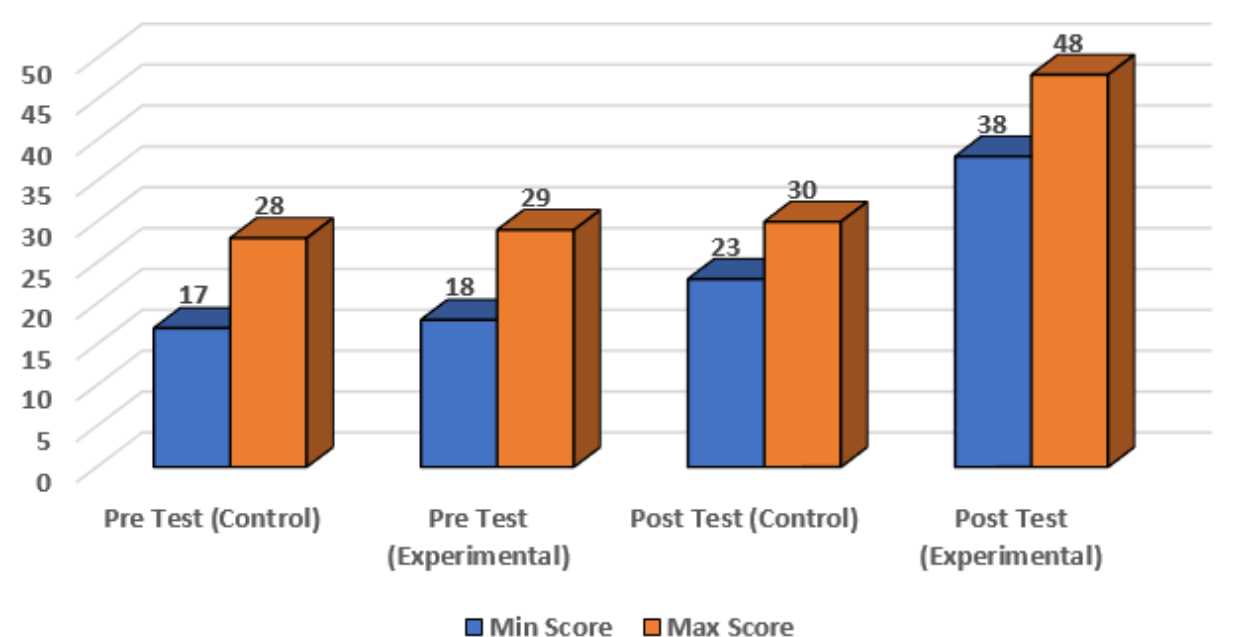

Figure 1. The overall minimum score and maximum score for control and experimental group between pre-test and post-test (maximum score $=63 \%)$

for the wrong answer. Marks obtained from multiple-choice questions and open-ended questions used to perform the ANCOVA analysis. The maximum score for multiple-choice questions were 30 marks while open-ended questions made up of 53 marks. Students' understanding of chemistry concepts was analysed based on the answer given by the students. Answers from pre-test and post-test were compared to identify the conceptual change among the students.

\section{RESULTS}

During the pre-test, ANCOVA result shown that there was no statistically significant different in the score between control and experimental group. For the post-test, result from the one-way ANCOVA shown that there was statistically significant main effect between experimental and control group $\left(\mathrm{F}(1,160)=167.82, \mathrm{p}<0.05 \eta_{\mathrm{p}}^{2}=\right.$ $0.512)$. The experimental group had shown an increment in the post-test mean value (Mexp= 72.68; $\mathrm{SDexp}=6.17)$ compare to the pre-test mean value $(\mathrm{Mexp}=61.56$; $\mathrm{SDexp}=6.65)$. Similarly, control group exhibited an increase in the mean value in the post-test $($ Mcon $=63.65$; SDcon $=7.74)$ compared to the pre-test mean value $($ Mcon $=61.11$; SDcon $=7.97)$. The partial eta square value of 0.512 indicates that $51.2 \%$ of the total variance in students' understanding of chemistry concepts post-test scores was due to the treatment itself. According to Cohen (1988), values between 0.5 to 0.8 is considered to be medium to large effect size. This signifies that nanoscience activities have added value in improving secondary school students' understanding of chemistry concepts. Table 1 illustrated the output of the ANCOVA analysis.

Aside from the inferential statistical analysis, students understanding of chemistry concepts were further analysed by using the response from the chemistry achievement test. Figure 1 shows the differences between the overall minimum and maximum score from the control and experimental group for the pre-test and post test result. In general, it shows that students in both the control and experimental group perform better in the post test. The minimum and maximum score for the control group do not show a noticeable difference in pre-test and post-test. For the experimental group, the difference between the minimum and maximum score before and after the treatment is evident. The difference for the score is nearly 20 marks after the students undergo the treatment. This gives a general picture that students from the control group have minimal improvement in mastering the chemistry concepts. Meanwhile, the mean score for the experimental group in the post test was nearly five marks higher than the control group $(\mathrm{Mexp}=47.18$, Mcon $=42.65)$. 


\section{Qualitative Analysis for the Open-Ended Questions}

For the first open-ended question, mainly control group students have provided correct answers to the questions that assessed the fundamental understanding inherent in the activities. For instance, for the question 'What type of particle found in water?' The majority (75.90\%) of the control group students provided an incorrect answer by indicating that the atom is particle found in water in the pre-test. However, in the post test many $(86.75 \%)$ have provided correct answer indicating molecule is the particle found in the water. In another question which was tested, 'At what temperature water changes to ice?', more than three-quarters of the students $(78.31 \%)$ provided an incorrect answer in the pre-test and the majority $(75.90 \%)$ provided a correct answer which is $0^{\circ} \mathrm{C}$, in the post test.

On the contrary, control group students notably identified unable to answer questions that assessed their ability to analyse the given situation. For instance, for the question 'The smell of curry cooking in the kitchen spreads to the living room. Based on the kinetic theory of matter, state the process involved. Explain your answer.' more than $80 \%$ of the students from the control group failed to provide correct answers in the pre-test and post-test. For this question, students manage to identify the process that takes place which is diffusion. However, they were not able to further explain the process from the perspective of kinetic theory. Students were not able to describe the movement of particles based on the situation given in the questions. They only managed to answer the question partially. This signified that students still not mastery the full set of chemistry concepts related to kinetic theory.

Meanwhile, during the pre-test, students from the experimental group showed a quiet similar trend as compared to the control group. Students in the experimental group possess to mastery the fundamental understanding inherent in the question but not for the question that required them to analyse and make a connection based on the situation provided in the question. In this question, the majority $(76.25 \%)$ of the students score between 2 to 4 marks in the pre-test, and this indicates that students still are not able to master the chemistry content well and have a poor understanding in the chemistry concept. On the other hand, after the treatment, the students from the experimental notably master the chemistry concepts better than before. The same question for instance, 'The smell of curry cooking in the kitchen spreads to the living room. Based on the kinetic theory of matter, state the process involved. Explain your answer.' was asked in the open-ended test, students from the experimental group were able to answer and explain it. During the post-test $78.75 \%$ of the students from the experimental group managed to score the full marks ( 3 marks) for this question. Students can explain the phenomenon provided based on the theory learned such as the particles move randomly from the region of high concentration to the region of low concentration. This manifests that students not only understand the chemistry concepts, the ability to analyse the question and relate the concepts learned and applied it to the questions asked. According to Holme et al. (2015), students that able to answer such question reflected that they understand the chemistry concept as here students were able to apply core chemistry ideas to chemistry situations that are novel to them (Transfer Fragment).

\section{DISCUSSION}

Concepts are the basic building blocks and are considered necessary for the structure of knowledge to organize their thinking and communication among people (Arends \& Kilcher, 2010). Hudgins et al. (2006) argued that understanding concepts could enhance the ability to learn subject matter knowledge in a meaningful way. A learner who has a clear view of conceptual ideas has better opportunity to learn and more importantly for meaningful learning to occur; students must engage in active learning which relates students' prior knowledge with the new knowledge through the learning activities that are designed to encourage students to make meaningful connections. Numerous studies demonstrated that understanding of chemistry concepts could be improved by using a constructivist approach (Demircioglu et al., 2005; Tal, 2004; Tobin \& Gallagher, 1987).

In this study, the understanding of chemistry concepts was evaluated using two methods, the multiple-choice questions, and open-ended questions. In presenting the overall understanding, the analysis was performed considering all these responses. The overall ANCOVA analysis performed indicates that the nanoscience activities significantly improved the respondents' understanding of chemistry concepts. The outcome suggests that students from the experimental group have a better understanding of chemistry concepts than the students from the control group. The higher mean score in the post test obtained by the experimental group students shown that the nanoscience laboratory activities effectively improved students' understanding of chemistry concepts than the more conventional approach. The significant improvement of students' understanding of chemistry concepts was also reflected in the open-ended responses. In the response, students manage to explain and provide a more scientific answer. The answer provided by the students showed that their understanding of the concepts tested has improved and they were able to apply the concepts learned in solving application questions. Evidence has shown that students had significantly mastered the concepts and showed improvement in mastering the chemistry concepts.

The significant difference obtained from this study signifies the advantage of nanoscience activities in improving the respondents' understanding of chemistry concepts. The pre-test results of the experimental group 
and control group indicated that respondents' understanding of chemistry concepts such as the structure of the atom and acids and bases concepts was low. This outcome is parallel with other studies reported earlier (CetinDindar \& Geban, 2017; Demircioglu et al., 2005; Levy Nahum, Hofstein, Mamlok-Naaman, \& Bar-Dov, 2004; Muhamad Damanhuri, Treagust, Won, \& Chandrasegaran, 2016) whereby students have a low understanding of chemistry concepts mentioned above.

The post-test demonstrated that the experimental group has a better understanding of chemistry concepts. This difference is probably due to the treatment of nanoscience activities that made them understand the chemical concepts on topics of acids and bases and structure of the atom. The laboratory work with nanoscience which was designed based on constructivist theory improved the respondents' understanding of chemistry concepts. Furlan (2009) investigated the impact of nanoscience on an understanding of chemistry concepts and reported that nanoscience improved students understanding. According to Jones et al. (2003), a significant improvement in understanding of chemistry-related concepts was noticed when students involved in nanoscience hands-on activities. Dori et al. (2014) mentioned that through nanoscience, students learn to apply and connect their chemical understanding to interdisciplinary aspects and everyday applications. This teaching approach helps students to transfer the knowledge in understanding basic chemistry concepts and their relevant applications.

School science laboratory provides opportunities for students to interact with materials to observe and understand the natural phenomenon of the world. Through the laboratory activities, it creates meaningful learning experiences for the student as they were provided with opportunities to construct their knowledge. The studentcentred nanoscience laboratory activities managed to facilitate the attainment of the cognitive, effective and practical goals as stated by Hofstein and Lunetta (2004). In summary, it can be concluded that the use of suitable teaching approach helps in improving students' understanding of chemistry concepts. For instance, by using the

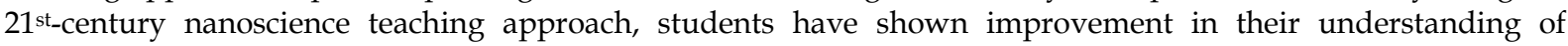
chemistry concepts. The nanoscience activities were formulated based on the constructivist theory and activity theory.

\section{CONCLUSION}

The outcome of the findings on the effectiveness of nanoscience activities which was measured based on the changes in understanding of chemistry concepts is not only a learning process, but it also enriches the students' development on their chemistry knowledge. These activities which are based on nanoscience activities further strengthens understanding of chemistry concepts among the students. The nanoscience teaching approach can be understood as an alternative way of teaching and learning for the chemistry lessons and at the same time enhance the laboratory skills where it guides students in carrying out their task in the laboratory and also support the understanding of chemistry concepts. Besides, the nanoscience activities conducted in laboratory were on the scale of nano. Therefore, this would be a new area for chemistry laboratory activities especially in a school setting where advance instrumentations are limited. Most importantly, these strategies are based in incorporating the 21 st-century science in which it extends students' needs to engage with the demands of science, rather than seeing chemistry as a boring, factual and boring subject. The results of the present study reinforce the idea that students can benefit from student-centred learning. Besides teachers could create a learning environment where students can participate and cooperate with peers to construct understanding about the chemistry through essential scientific practices (Hand, 2008).

\section{REFERENCES}

Agung, S., \& Schwartz, M. S. (2007). Students' understanding of conservation of matter, stoichiometry and balancing equations in Indonesia. International Journal of Science Education, 29(13), 1679-1702. https:// doi.org/10.1080/09500690601089927

Allamel-Raffin, C. (2011). The meaning of a scientific image: Case study in nanoscience a semiotic approach. NanoEthics, 5(2), 165-173. https:/ / doi.org/10.1007/s11569-011-0123-1

Arends, D., \& Kilcher, A. (2010). Teaching for student learning: Becoming an accomplished teacher. New York: Routledge.

Aydeniz, M., \& Kotowski, E. L. (2012). What do middle and high school students know about the particulate nature of matter after instruction? Implications for practice. School Science and Mathematics, 112(2), 59-65. https:// doi.org/10.1111/j.1949-8594.2011.00120.x

Ben-Zvi, R., Eylon, B., \& Silberstein, J. (1988). Theories, principles and laws. Education in Chemistry, 65(25), 89-92.

Blonder, R., \& Dinur, M. (2012). Teaching nanotechnology using student-centered pedagogy for increasing students' continuing motivation. Journal of Nano Education, 3(1), 51-61. https://doi.org/10.1166/jne.2011. 1016 
Blonder, R., \& Sakhnini, S. (2012). Teaching two basic nanotechnology concepts in secondary school by using a variety of teaching methods. Chemistry Education Research and Practice, 13(4), 500-516. https://doi.org/10. 1039/C2RP20026K

Bradley, E. L., Castle, L., \& Chaudhry, Q. (2011). Applications of nanomaterials in food packaging with a consideration of opportunities for developing countries. Trends in Food Science \& Technology, 22(11), 604-610. https:/ / doi.org/10.1016/j.tifs.2011.01.002

Burns, J. R. (1982). An evaluation of 6th and 7th form chemistry in terms of the needs of the students and the community: Report to the Department of Education. Wellington, New Zealand: Department of Education.

Canpolat, N. (2006). Turkish undergraduates' misconceptions of evaporation, evaporation rate, and vapour pressure. International Journal of Science Education, 28(15), 1757-1770. https://doi.org/10.1080/ 09500690600779957

Cetin-Dindar, A., \& Geban, O. (2017). Conceptual understanding of acids and bases concepts and motivation to learn chemistry. The Journal of Educational Research, 110(1), 85-97. https:/ / doi.org/10.1080/00220671.2015. 1039422

Chandrasegaran, A. L., Treagust D. F., \& Mocerino, M. (2007). The development of a two-tier multiple-choice diagnostic instrument for evaluating secondary school students' ability to describe and explain chemical reactions using multiple levels of representation. Chemistry Education Research and Practice, 8(3), 293-307. https:/ / doi.org/10.1039/B7RP90006F

Chari, D. N., Howard, R., \& Bowe, B. (2012). Disciplinary identity of nanoscience and nanotechnology research: A study of postgraduate researchers' experiences. International Journal for Digital Society, 3(1), 619-616. https:/ / doi.org/10.20533/ijds.2040.2570.2012.0074

Cheung, D. (2011). Evaluating student attitudes toward chemistry lessons to enhance teaching in the secondary school. Educ. quim, 22(2), 117-122. https:/ / doi.org/10.1016/S0187-893X(18)30123-X

Chiu, M. H. (2004). An investigation of exploring mental models and causes of secondary school students' misconceptions in acids-bases, particle theory, and chemical equilibrium. Annual report to the National Science Council in Taiwan, Taiwan: National Science Council.

Chiu, M. H. (2007). A national survey of students' conceptions of chemistry in Taiwan. International Journal of Science Education, 29(4), 421-454. https:/ / doi.org/10.1080/09500690601072964

Chua, K. H \& Karpudewan, M. (2017). Facilitating primary school students' understanding of water cycle through guided inquiry-based learning. In M. Karpudewan, A. N. M. Zain, \& A. L. Chandrasegaran (Eds.), Overcoming students' misconceptions in science strategies and perspectives from Malaysia (pp. 29 - 49). Singapore: Springer. https://doi.org/10.1007/978-981-10-3437-4_3

Chua, K. H., Karpudewan, M., \& Chandrakesan, K. (2017). Climate change activities: A possible means to promote understanding and reduce misconceptions about acid rain, global warming, greenhouse effect and ozone layer depletion among secondary school students. In M. Karpudewan, A. N. M. Zain, \& A. L. Chandrasegaran (Eds.), Overcoming students' misconceptions in science strategies and perspectives from Malaysia (pp. 323 - 344). Singapore: Springer. https:/ / doi.org/10.1007/978-981-10-3437-4_17

Cohen, J. (1988). Statistical power analysis: A computer program: Routledge.

Cohen, L., Manion, L., \& Morrison, K. (2007). Research methods in education (6th ed.). New York, USA: Taylor \& Francis. https:/ / doi.org/10.4324/9780203029053

Creswell, J. W. (2014). Research design qualitative, quantitative, and mixed methods approaches (4th ed.). California, USA: SAGE Publications.

Dai, Y. (2004). Using new teaching strategies to improve teaching and learning in organic chemistry. The China Papers, 4(4), 6-9.

Demircioglu, G., Ayas, A., \& Demircioglu, H. (2005). Conceptual change achieved through a new teaching program on acids and bases. Chemistry Education Research and Practice, 6(1), 36-51. https://doi.org/10.1039/ B4RP90003K

Dori, Y. J., Dangur, V., Avargil, S., \& Peskin, U. (2014). Assessing advanced high school and undergraduate students' thinking skills: The chemistry--from the nanoscale to microelectronics module. Journal of Chemical Education, 91(9), 1306-1317. https:/ / doi.org/10.1021/ed500007s

Furlan, P. Y. (2009). Engaging students in early exploration of nanoscience topics using hands-on activities and scanning tunneling microscopy. Journal of Chemical Education, 86(6), 705-711. https://doi.org/10.1021/ ed086p705 
Gabel, D. L. (1988). The complexity of chemistry and implications for teaching. In B. J. Fraser \& K. G. Tobin (Eds.), International Handbook of Science Education (pp. 233-249). Great Britain: Klewer Academic Press. https://doi.org/10.1007/978-94-011-4940-2_15

Gabel, D. L. (1993). Use of the particle nature of matter in developing conceptual understanding. Journal of Chemical Education, 70(3), 193-194. https://doi.org/10.1021/ed070p193

Gay, L. R., Mills, G. E., \& Airasian, P. (2009). Educational research: Competencies is and applications (9th ed.). New Jersey: Pearson.

Ghattas, N. I., \& Carver, J. S. (2012). Integrating nanotechnology into school education: A review of the literature. Research in Science and Technological Education, 30(3), 271-284. https:/ / doi.org/10.1080/02635143.2012.732058

Hand, B. M. (2008). Introducing the science writting heuristic approach. In B. M. Hand (Ed.), Science inquiry, argument and language: A case study for the science writing heuristic Rotterdam, Netherlands: SENSE Publishers.

Hey, J. H. G., Joyce, C. K., Jennings, K. E., Kalil, T., \& Grossman, J. C. (2009). Putting the discipline in interdisciplinary: Using speedstorming to teach and initiate creative collaboration in nanoscience. Journal of Nano Education, 1(1), 75-85. https:/ / doi.org/10.1166/jne.2009.012

Hofstein, A., \& Lunetta, V. N. (2004). The laboratory in science education: Foundations for the twenty-first century. Science Education, 88(1), 28-54. https://doi.org/10.1002/sce.10106

Holme, T. A., Luxford, C. J., \& Brandriet, A. (2015). Defining conceptual understanding in general chemistry. Journal of Chemical Education, 92(9), 1477-1483. https:/ / doi.org/10.1021/acs.jchemed.5b00218

Huang, W. C. (2004). The types and causes of misconceptions of elementary students on acids-bases. Annual Report to the National Science Council in Taiwan, Taiwan: National Science Council.

Hudgins, D. W., Prather, E. E., Grayson, D. J., \& Smits, D. P. (2006). Effectiveness of collaborative ranking tasks on student understanding of key astronomy concepts. Astronomy Education Review, 5(1), 1-22. https://doi.org/10.3847/ AER2006001

Ibrahim, N. R. M., \& Karpudewan, M. (2013). Nanoscience activities improves students' attitude towards learning biology. Paper presented at the 5th International Conference on Science and Mathematics Education, CoSMEd 2013, Penang, Malaysia.

Johnson, D. W., \& Johnson, R. T. (1989). Cooperation and competition: Theory and research. Edina, MN: Interaction Book Co.

Jones, M. G., Andre, T., Superfine, R., \& Taylor, R. (2003). Learning at the nanoscale: The impact of students' use of remote microscopy on concepts of viruses, scale, and microscopy. Journal of Research in Science Teaching, 40(3), 303-322. https:/ / doi.org/10.1002/tea.10078

Kala, N., Yaman, F., \& Ayas, A. (2013). The effectiveness of Predict-Observe-Explain technique in probing students' understanding about acid-base chemistry: A case for the concepts of $\mathrm{pH}, \mathrm{pOH}$ and strength. International Journal of Science and Mathematics Education, 11(1), 555-574. https:/ / doi.org/10.1007/s10763-012-9354-Z

Karpudewan, M., Treagust, D. F., Mocerino, M., Won, M., \& Chandrasegaran, A. L. (2015). Investigating high school students' understanding of chemical equilibrium concepts. International Journal of Environmental $\mathcal{E}$ Science Education, 10(6), 845-863. https:/ / doi.org/10.12973/ijese.2015.280a

Kennedy, M. M. (1998). Education reform and subject matter knowledge. Journal of Research in Science Teaching, 35(3), 249-263. https:/ / doi.org/10.1002/(SICI)1098-2736(199803)35:3<249::AID-TEA2>3.0.CO;2-R

Kirbulut, Z. D., \& Beeth, M. E. (2013). Representations of fundamental chemistry concepts in relation to the particulate nature of matter. International Journal of Education in Mathematics, Science and Technology, 1(2), 96106.

Kozma, R. (2003). The material features of multiple representations and their cognitive and social affordances for science understanding. Learning and Instruction, 13(2), 205-226. https://doi.org/10.1016/S09594752(02)00021-X

Laherto, A. (2012). Nanoscience education for scientific literacy: Opportunities and challenges in secondary school and in out-of-school settings. (Doctoral Dissertation Unpublished thesis), University of Helsinki, Helsinki, Finland. https://doi.org/10.5617/nordina.537

Levy Nahum, T., Hofstein, A., Mamlok-Naaman, R., \& Bar-Dov, Z. (2004). Can final examinations amplify students' misconceptions in chemistry? Chemistry Education Research and Practice, 5(3), 301-325. https://doi.org/10.1039/B4RP90029D

Levy Nahum, T., Mamlok-Naaman, R., Hofstein, A., \& Krajcik, J. S. (2007). Developing a new teaching approach for the chemical bonding concept aligned with current scientific and pedagogical knowledge. Science Education, 91(4), 579-603. https://doi.org/10.1002/sce.20201 
Levy Nahum, T., Mamlok-Naaman, R., Hofstein, A., \& Taber, K. S. (2010). Teaching and learning the concept of chemical bonding. Studies in Science Education, 46(2), 179-207. https://doi.org/10.1080/03057267.2010. 504548

Mbajiorgu, N., \& Reid, N. (2006). Factors influencing curriculum development in higher education physics: A Physical sciences practice guide. Hull: Higher Education Academy, Physical Sciences Centre Press.

McWeeny, R. (2007). Atoms, molecules, matter- the stuff of chemistry. Italy.

Mehraban, Z. (2016). Investigating into the learning process of nanoscience and technology concepts based on the constructivist learning. Journal of Fundamental and Applied Sciences, 8(3S), 2158-2171.

Meyer, H. (2005). Is it molecules? Again! A review of students' learning about particle theory. The Chemical Education Journal, 9(2), 9-10.

Muhamad Damanhuri, M. I., Treagust, D. F., Won, M., \& Chandrasegaran, A. L. (2016). High school students' understanding of acid-base concepts: An ongoing challenge for teachers. International Journal of Environmental and Science Education, 11(1), 9-27. https:/ / doi.org/10.12973/ijese.2015.284a

National Nanotechnology Initiative. (2008). Nanotechnology: Big things from a tiny world. Arlington, VA: NNI Publications and Reports, Educational and Societal Dimensions.

Osman, K., \& Sukor, N. S. (2013). Conceptual understanding in secondary school chemistry: A discussion of the difficulties Experienced by students. American Journal of Applied Sciences, 10(5), 433-441. https:// doi.org/10.3844/ajassp.2013.433.441

Ozmen, H. (2004). Some student misconceptions in chemistry: A literature review of chemical bonding. Journal of Science Education and Technology, 13(2), 147-159. https:/ / doi.org/10.1023/B:JOST.0000031255.92943.6d

Ozmen, H., Demircioglu, G., Burhan, Y., Naseriazar, A., \& Demircioglu, H. (2012). Using laboratory activities enhanced with concept cartoons to support progression in students' understanding of acid-base concepts. Asia-Pacific Forum on Science Learning and Teaching, 13(1), Article 8.

Park, E. J., Light, G., Swarat, S., \& Denise, D. (2009). Understanding learning progression in student conceptualization of atomic structure by variation theory for learning. Paper presented at the Learning Progressions in Science Conference, Iowa City, Iowa.

Salame, I. I., Sarowar, S., Begum, S., \& Krauss, D. (2011). Students' alternative conceptions about atomic properties and the periodic table. The Chemical Educator, 16, 190-194. https:/ / doi.org/10.1333/s00897112375a

Santiago, L., \& Morell, G. (2006). The need for promoting nanotechnology awareness in higher education. Cuaderno de Investigación en la Educación, 21, 91-102.

Sarikaya, M. (2007). Prospective teachers' misconceptions about the atomic structure in the context of electrification by friction and an activity in order to remedy them. International Education Journal, 8(1), 40-63.

Schank, P., Wise, A., Stanford, T., \& Rosenquist, A. (2009). Can high school students learn nanoscience? An evaluation of the viability and impact of the nanoscience curriculum. Menlo Park, CA: SRI International.

Sequeira, M., \& Leite, L. (1991). Alternative conceptions and history of science in physics teacher education. Science Education, 75(1), 45-56. https://doi.org/10.1002/sce.3730750105

Shadish, W. R., Cook, T. D., \& Campbell, D. T. (2002). Experimental and quasi-experimental designs for generalized causal inference (2nd ed.). Boston: Houghton Mifflin.

Shamuganathan, S. \& Karpudewan, M. (2017). Science writing heuristics embedded in green chemistry: a tool to nurture environmental literacy among pre-university students. Chemistry Education Research and Practice, 18(2), 386-396. https:// doi.org/10.1039/C7RP00013H

Sim, J. H., \& Daniel, E. G. S. (2014). Representational competence in chemistry: A comparison between students with different levels of understanding of basic chemical concepts and chemical representations. Cogent Education, 1(1), 991180. https:/ / doi.org/10.1080/2331186X.2014.991180

Snyder, R. F. (2000). The relationship between learning styles/multiple intelligences and academic achievement of high school students. The High School Journal, 83(2), 11-20.

Supasorn, S. (2012). Enhancing undergraduates' conceptual understanding of organic acid-base-neutral extraction using inquiry-based experiments. Procedia - Social and Behavioral Sciences, 46, 4643-4650. https:/ / doi.org/10.1016/j.sbspro.2012.06.311

Surif, J., Ibrahim, N. H., \& Mokhtar, M. (2012). Conceptual and procedural knowledge in problem solving. Procedia - Social and Behavioral Sciences, 56, 416-425. https:/ / doi.org/10.1016/j.sbspro.2012.09.671

Tal, R. T. (2004). Using a field trip to a wetland as a guide for conceptual understanding in environmental education - A case study of a pre-service teacher's research. Chemistry Education Research and Practice, 5(2), 127-142. https:/ / doi.org/10.1039/B4RP90016B 
Tobin, K. G., \& Gallagher, J. J. (1987). What happens in high school science classrooms? Journal of Curriculum Studies, 19(6), 549-560. https:/ / doi.org/10.1080/0022027870190606

Varadan, V. K., Pillai, A. S., Mukherji, D., Dwivedi, M., \& Chen, L. (2010). Introduction Nanoscience and Nanotechnology in Engineering (pp. 1-25). Singapore: World Scientific Publishing Co. Pte. Ltd. https:// doi.org/10.1142/7364

Vockell, E. L., \& Asher, J. W. (1995). Educational Research (2nd ed.). Ohio, USA: Prentice Hall.

Yakmaci-Guzel, B., \& Adadan, E. (2013). Use of multiple representations in developing preservice chemistry teachers' understanding of the structure of matter. International Journal of Environmental and Science Education, 8(1), 109-130.

Zangori, L., Vo, T., Forbes, C. T., \& Schwarz, C. V. (2017). Supporting 3rd-grade students model-based explanations about groundwater: A quasiexperimental study of a curricular intervention. International Journal of Science Education, 39(11), 1421-1442. https:/ / doi.org/10.1080/09500693.2017.1336683

\section{http://www.ejmste.com}

